\title{
Synthesis of poly- and oligo(hydroxyalkanoate)s by deep-sea bacteria, Colwellia spp., Moritella spp., and Shewanella spp
}

\author{
Keiji Numata ${ }^{1}$, Kumiko Morisaki ${ }^{1}$, Satoshi Tomizawa ${ }^{1}$, Misato Ohtani $^{2}$, Taku Demura ${ }^{2}$, Masayuki Miyazaki ${ }^{3}$, \\ Yuichi $\mathrm{Nogi}^{3}$, Shigeru Deguchi ${ }^{3}$ and Yoshiharu Doi ${ }^{4}$
}

The production of poly(hydroxyalkanoate)s (PHAs) as ecofriendly bioplastics by various deep-sea bacteria (4 types of Colwellia spp., 11 types of Moritella spp., and 18 types of Shewanella spp.) from glucose, fructose, gluconate, or from one of the several plant oils as the sole source of carbon was examined at atmospheric pressure. Some of the deep-sea bacteria successfully accumulated PHAs that had a wide range of molecular weights and contained 3-hydroxybutyrate, 3-hydroxyvalerate, and the other hydroxyalkanoate units. Furthermore, with a plant oil as its sole source of carbon, Shewanella surugensis produced low-molecular weight oligomeric PHAs. These results provide important and basic information regarding the production of PHAs by deep-sea bacteria and on the diversity of PHA synthase enzymes in nature.

Polymer Journal (2013) 45, 1094-1100; doi:10.1038/pj.2013.25; published online 6 March 2013

Keywords: biosynthesis; deep-sea bacteria; poly(hydroxyalkanoate).

\section{INTRODUCTION}

Deep-sea bacteria that grow preferentially or exclusively at high hydrostatic pressures and low temperatures have been discovered in various ocean trenches, such as the Mariana Trench. Because of their unique requirements in terms of pressure, temperature, and nutrients, deep-sea bacteria have recently been identified as important bioresources that are capable of providing novel chemicals, enzymes, or genes. It has been reported that the aerobic and anaerobic pathways of fatty-acid biosynthesis in deep-sea bacteria are mutually exclusive of one another and that they differ from the comparable pathways in other organisms. ${ }^{1,2}$ Additionally, the biosynthesis of polyunsaturated fatty-acids (PUFAs) such as $(5 Z, 8 Z, 11 Z, 14 Z, 17 Z)$-icosa-5,8,11,14, 17-pentaenoic acid (EPA) or $(4 Z, 7 Z, 10 Z, 13 Z, 16 Z, 19 Z)$-docosa$4,7,10,13,16,19$-hexaenoic acid (DHA) by fermentation with deepsea bacteria has been an attractive process because of the importance of these compounds to human health. ${ }^{3}$ Bacteria of the genus Moritella biosynthesize DHA, whereas those of the genera Colwellia and Shewanella produce EPA. ${ }^{4}$ Bacteria of the genus Colwellia are strictly psychrophilic (active below $20^{\circ} \mathrm{C}$ ), and they produce extracellular polymers relevant to biofilm formation and cryoprotection. ${ }^{5}$ Also, enzymes from Colwellia species can degrade polymeric compounds, indicating that Colwellia species might provide a novel method for assimilating polymeric biomass. ${ }^{6}$ Bacteria of the genus Shewanella are deep-sea bacteria that are capable of biosynthesizing hydrocarbons, such as polyolefins. ${ }^{7}$ These various metabolic pathways for fatty-acid biosynthesis suggest that it should be possible to produce new biochemicals and biopolymers through fermentations with deep-sea bacteria.

Poly(hydroxyalkanoate)s (PHAs) are biodegradable polyesters that are biosynthesized by a variety of bacteria as intracellular materials for the storage of carbon, and their thermal, mechanical, and biological characteristics have been studied extensively. ${ }^{8-10}$ The mechanical properties of PHAs can be improved by means of drawing techniques, resulting in a tensile strength of as high as $1.32 \mathrm{GPa}$, an elongation-to-the-break of $31 \%$, and a Young's modulus for the drawn PHA fiber of $8.1 \mathrm{GPa} .{ }^{11}$ These improved mechanical properties of PHAs are comparable with those of industrial samples of polyethylene and polypropylene, and therefore PHAs are an attractive group of materials with respect to their environmental impact, carbon dioxide emissions, and mechanical strength.

PHA is synthesized via glycosylation or $\beta$-oxidation pathway (Figure 1). The genes for the synthesis of PHAs reside within an operon that includes a $\beta$-ketothiolase (phaA), an acetoacetylcoenzyme A (CoA) reductase $(p h a B)$, and a synthase $(p h a C) .{ }^{12}$ The thiolase and reductase contribute to synthesis of the monomeric substrate 3-hydroxybutyryl CoA, and the synthase polymerizes this monomer to form PHAs. ${ }^{12}$ With respect to the synthesis of PHAs by the $\beta$-oxidation pathway, phaJ and $f a b G$ genes encoding $(R)$-specific

${ }^{1}$ Enzyme Research Team, RIKEN Biomass Engineering Program, RIKEN, Saitama, Japan; ${ }^{2}$ Cellulose Production Research Team, RIKEN Biomass Engineering Program, RIKEN, Yokohama, Japan; ${ }^{3}$ Institute of Biogeosciences, Japan Agency for Marine-Earth Science and Technology (JAMSTEC), Yokosuka, Japan and ${ }^{4}$ RIKEN Research Cluster for Innovation, RIKEN, Saitama, Japan

Correspondence: Dr K Numata, Enzyme Research Team, RIKEN Biomass Engineering Program, RIKEN, 2-1 Hirosawa, Wako-shi, Saitama 351 0198, Japan. E-mail: keiji.numata@riken.jp

Received 20 January 2013; revised 30 January 2013; accepted 1 February 2013; published online 6 March 2013 


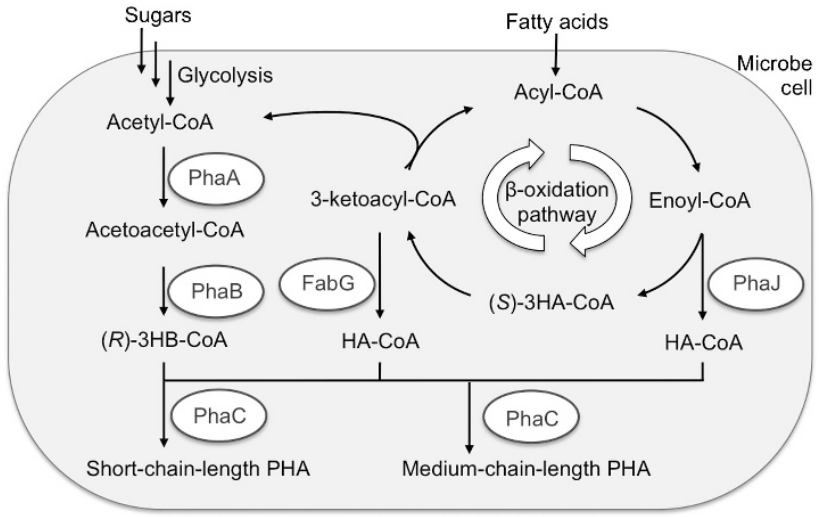

Figure 1 Pathway for the biosynthesis of PHA from sugars and fatty acids. PhaA, $\beta$-ketothiolase; PhaB, acetoacetyl-coenzyme A reductase; PhaC, PHA synthase; FabG, 3-ketoacyl acyl carrier protein (ACP) reductase; PhaJ, enoyl-coenzyme A hydratase. A full color version of this figure is available at Polymer Journal online.

2-enoyl-CoA hydratase and 3-ketoacyl-acyl carrier protein reductase are known to be responsible for converting 3-enoyl-CoA and 3-ketoacyl-CoA into $(R)$-3-hydroxyacyl-CoA (Figure 1). ${ }^{13,14} \mathrm{PhaC}$ is the key enzyme for the synthesis of high-performance PHAs, because its substrate specificity and specific activity affect the monomeric compositions of the resulting PHA copolymers as final products. ${ }^{15}$

In attempts to synthesize new types of PHA, numerous researchers have sought examples of $\mathrm{PhaC}$ that show substrate specificities that differ from those of known types of PhaC. However, no attempts have been made to produce PHAs by using deep-sea bacteria as sources of new PhaCs. Also, the biosynthesis pathway of fatty acids in deep-sea bacteria differ from the comparable pathways in soil bacteria, implying a potential to synthesize new monomers via $\beta$-oxidation pathway. ${ }^{1,2}$ We therefore selected and characterized a number of deep-sea strains, namely, 4 Colwellia spp., 11 Moritella spp., and 18 Shewanella spp., and we examined their production of PHAs from various carbon sources. The findings of this study are expected to provide important and basic information regarding the production of PHAs by deep-sea bacteria, in addition to improving our knowledge of novel PhaCs.

\section{EXPERIMENTAL PROCEDURES}

\section{Cultivation of deep-sea bacteria}

Colwellia spp. and Shewanella spp. were isolated and stored by the Japan Agency for Marine-Earth Science and Technology. Moritella spp. were obtained from RIKEN BioResource Center. All the strains that we used in this study are listed in Supplementary Table S1. These strains were plated on marine agar (Difco; Becton, Dickinson and Co., Franklin Lakes, NJ, USA) and incubated at the optimal temperature for $72 \mathrm{~h}$. The optimal temperatures for the various Moritella spp., Colwellia spp., and Shewanella spp. are listed in Supplementary Table S1.

\section{PHA production}

The production of PHAs by 11 types of Moritella spp., 4 types of Colwellia spp., and 18 types of Shewanella spp. was examined on a small scale $(4 \mathrm{ml})$ to screen for PHA-producing strains. Strains were precultured in a marine broth medium (Difco) under aerobic conditions in 10-ml tubes with constant shaking at $140 \mathrm{rpm}$ for $48 \mathrm{~h}$. The PHA-production phase was carried out in MM (mineral medium) medium containing glucose, fructose, gluconate (sodium gluconate), or soybean oil $\left(20 \mathrm{gl}^{-1}\right)$ as the sole source of carbon. Fermentations were performed at the optimal temperature with constant shaking at 140 r.p.m. for $72 \mathrm{~h}$ under aerobic conditions. ${ }^{16}$ The MM medium contained $2.80 \mathrm{gl}^{-1}$ of $\mathrm{KH}_{2} \mathrm{PO}_{4}, 3.32 \mathrm{gl}^{-1} \mathrm{Na}_{2} \mathrm{HPO}_{4}, 0.54 \mathrm{gl}^{-1}\left(\mathrm{NH}_{2}\right)_{2} \mathrm{CO}$, $0.25 \mathrm{gl}^{-} \mathrm{MgSO}_{4} \cdot 7 \mathrm{H}_{2} \mathrm{O}, 19.45 \mathrm{gl}^{-1} \mathrm{NaCl}$, and $1.0 \mathrm{mll}^{-1}$ trace elements, consisting of $0.22 \mathrm{gl}^{-1} \mathrm{CoCl}_{2} \cdot 6 \mathrm{H}_{2} \mathrm{O}, 9.70 \mathrm{gl}^{-1} 1^{-1} \mathrm{FeCl}_{3}, 7.80 \mathrm{gl}^{-1} \mathrm{CaCl}_{2}$, $0.12 \mathrm{gl}^{-1} \mathrm{NiCl}_{2} \cdot 6 \mathrm{H}_{2} \mathrm{O}, 0.11 \mathrm{gl}^{-1} \mathrm{CrCl}_{3} \cdot 6 \mathrm{H}_{2} \mathrm{O}$, and $0.16 \mathrm{gl}^{-1} \mathrm{CuSO}_{4} \cdot 5 \mathrm{H}_{2} \mathrm{O}$. For larger-scale PHA production, strains were precultured in a marine broth medium (Difco) under aerobic conditions in a 10-ml tube with constant shaking at $140 \mathrm{rpm}$ for $48 \mathrm{~h}$. PHA production was carried out in MM medium supplemented with $20 \mathrm{gl}^{-1}$ of glucose, fructose, gluconate (sodium gluconate), jatropha oil, or soybean oil as the sole source of carbon in a 500-ml shaking flask containing $100 \mathrm{ml}$ of medium at the optimal temperature with constant shaking at 140 r.p.m. for $96 \mathrm{~h}$ under aerobic conditions. ${ }^{16}$ After cultivation, the collected cells were washed with MilliQ water and then ethanol to remove residual carbon sources and salts and then lyophilized. The lyophilized cells were weighed, and the accumulated PHAs were extracted from the dried cells with chloroform for $72 \mathrm{~h}$ at $70^{\circ} \mathrm{C}$, and then purified by precipitation with hexane. To determine their PHA content, the dry cells (before PHA extraction) were subjected to methanolysis with a solution consisting of $1.7 \mathrm{ml}$ of methanol, $0.3 \mathrm{ml}$ of $98 \%$ sulfuric acid, and $2.0 \mathrm{ml}$ of chloroform at $100^{\circ} \mathrm{C}$ for $140 \mathrm{~min}$ to convert the constituents into their methyl esters. The addition of $1.0 \mathrm{ml}$ of water to the reaction mixture induced phase separation. The lower chloroform layer was subjected to gas chromatographic (GC) analysis on a Shimadzu GC-17A system equipped with Neutra Bond-1 capillary column $(30 \mathrm{~m} \times 0.25 \mathrm{~mm})$ and a flame-ionization detector (Shimadzu Scientific Instruments, Kyoto, Japan). The PHA content was quantitatively determined through detection of the methyl esters of $(R)$-3-hydroxybutyrate $(3 \mathrm{HB})$ and $(R)-3$-hydroxyvalerate (3HV) units by GC and from the weight of the dry cells.

\section{Characterization of PHAs}

The purified PHAs were characterized with respect to their molecular weights and chemical structures. The molecular weights of the polymers were determined by using a gel-permeation chromatography system (RI-2031, PU-2086, AS-2055, C0-2065; JASCO, Tokyo, Japan) with a Shodex K-806 column (Showa Denko, Tokyo, Japan) at $40^{\circ} \mathrm{C}$. Chloroform was used as the eluent at a flow rate of $0.8 \mathrm{ml} \mathrm{min}{ }^{-1}$, and the concentration of the samples was approximately $1.0 \mathrm{mg} \mathrm{ml}^{-1}$. The molecular weight was estimated by comparison to polystyrene standards. The molecular weights of the nine polystyrene standards that we used were $3148843,1074876,460595,156528,66001$, 28517, 10112,3252 , and $1319 \mathrm{~g} \mathrm{~mol}^{-1}$, respectively. The PHAs were also analyzed by ${ }^{1} \mathrm{H}$ nuclear magnetic resonance (NMR) spectroscopy (JNMExcalibur270; JEOL, Ltd, Tokyo, Japan) to determine their precise chemical structures and compositions.

\section{Classification of PhaC genes}

Multiple alignment of samples of $\mathrm{PhaC}$ genes from Ralstonia eutropha (Cupriavidus necator, YP_725940), Aeromonas caviae (Aeromonas punctate, BAA21815), Shewanella halifaxensis HAW-EB4 (YP_001674210.1), Shewanella pealeana (YP_001501610.1), and Colwellia psychrerythraea 34H (YP_270743.1) was achieved by using ClustalW2 software (European Bioinformatics Institute, Cambridge, UK). The amino-acid identities and similarities were calculated by means of the BLAST algorithm. ${ }^{17}$

\section{RESULTS AND DISCUSSION}

\section{PHA productivity of deep-sea bacteria}

Production of PHAs by 4 types of Colwellia spp., 11 types of Moritella spp., and 18 types of Shewanella spp. was examined on a small scale $(4 \mathrm{ml})$ in $\mathrm{MM}$ medium supplemented with $20 \mathrm{gl}^{-1}$ of glucose, fructose, gluconate (sodium gluconate), or with soybean oil as the sole source of carbon. The PHA contents of the bacteria were characterized by means of GC as proportions of the weights of the dry cells (Supplementary Tables S2-S4). Colwellia spp. other than Colwellia sp. strain JAMM-0421 showed no cell growth or PHA production (Supplementary Table S2). Colwellia sp. strain JAMM0421 produced PHAs when glucose, fructose, or soybean oil was used as the sole source of carbon. In some cases, Moritella spp. showed cell growth and PHA productivity, as listed in Supplementary Table S3. 
The PHA contents of Moritella spp. were $<1 \%$ and were lower than those of Colwellia sp. strain JAMM-0421. The Shewanella spp. also showed relatively low PHA productivities ( $<1 \%$ PHA content), and these were independent of the type of carbon source or the strain. The results of these studies (Supplementary Tables S2-S4) did allow us to select three strains, a Colwellia sp. (JAMM0421), a Moritella sp. (JCM21335), and a Shewanella sp., S. surugensis (JAMM-0386), for further studies because these strains produced higher PHA contents than did other species of each respective genus.

\section{PHA production by a Colwellia sp., a Moritella sp., and \\ S. surugensis}

Three deep-sea strains, a Colwellia sp. (JAMM-0421), a Moritella sp. (JCM21335), and S. surugensis (JAMM-0036), were characterized in terms of their abilities to synthesize PHAs from glucose, fructose, gluconate, jatropha oil, or from soybean oil as the sole source of carbon in 100-ml-scale cultures at the appropriate optimal temperatures for $96 \mathrm{~h}$ (Table 1). The compositions of soybean oil and jatropha oil differ as listed in Supplementary Table S5, which would affect PHA productivity of the deep-sea strains. On the basis of the ${ }^{1} \mathrm{H}$ NMR spectra (Figure 2), Colwellia sp. (JAMM-0421) accumulated poly $((R)-$ 3-hydroxybutyrate-co- $(R)$-3-hydroxyvalerate) ( $\mathrm{P}(3 \mathrm{HB}-c o-3 \mathrm{HV})$ ) when glucose, fructose, jatropha oil, or soybean oil was used as the sole source of carbon. The accumulation of PHA by Colwellia sp. (JAMM0421) fed with plant oils resulted in higher PHA contents than those produced by other deep-sea bacteria (Table 1). The monomer composition of the resulting PHA was characterized by means of ${ }^{1} \mathrm{H}$ NMR spectroscopy (Figure 2); this showed that the $3 \mathrm{HV}$ contents ranged from 2.4 to $29.0 \mathrm{~mol} \%$, based on the integration of the peaks corresponding to the methyl protons ( 3 and 7 in Figure 2). The number-average molecular weights of the $\mathrm{P}(3 \mathrm{HB}-c o-3 \mathrm{HV})$ synthesized by Colwellia sp. strain JAMM-0421 ranged from $170 \times 10^{3}$ to $340 \times$ $10^{3} \mathrm{~g} \mathrm{~mol}^{-1}$ (Table 1 and Figure $3 \mathrm{~b}$ ); these values are in the normal range of molecular weights for bacterial polyesters. With respect to productivity, monomeric composition, and molecular weight of PHA, Colwellia sp. strain JAMM-0421 showed no obvious differences from soil bacteria. ${ }^{18}$

Although the Moritella sp. strain JCM21335 also produced P(3HBco-3HV) with a number-average molecular weight of $120 \times$ $10^{3} \mathrm{~g} \mathrm{~mol}^{-1}$ from fructose (Figures 3f and 4a), no PHA accumulation was detected when glucose and gluconate were used as the sole source of carbon (Table 1). Moritella sp. strain JCM21335 produced polymeric materials with number-average molecular weights of $1000-30000 \mathrm{~g} \mathrm{~mol}^{-1}$ from soybean oil or jatropha oil (Figures $3 \mathrm{~d}$ and e). The ${ }^{1} \mathrm{H}$ NMR spectra of the polymers produced from plant oils by Moritella sp. strain JCM21335 showed that no $3 \mathrm{HB}$ and $3 \mathrm{HV}$ units were present. However, methine, methylene, and methyl protons that could be assigned to hydroxyalkanoate units were detected (Figure $4 \mathrm{~b}$ ). The methylene peaks ( $\delta=2.0-3.0$ p.p.m.) were assigned to the methylene protons of the main chains, in accord with previous report. ${ }^{18,19}$ Thus, the Moritella sp. strain JCM21335 produced polymers with different main chain architectures depending on the source of carbon. Generally, sugars and fatty acids are processed to PHA mainly via glycosylation and $\beta$-oxidation pathways, respectively. Based on nature of the synthesized polymers, the PhaC of the Moritella sp. appears to have different substrate specificity, especially along the main-chain direction, from that of known PhaCs, such as those of Ralstonia eutropha or Aeromonas caviae. R. eutropha and A. caviae are known as typical soil bacteria to produce PHA. ${ }^{12,20}$
Table 1 PHA accumulation by three types of deep-sea bacteria with various sources of carbon

\begin{tabular}{|c|c|c|c|c|c|c|}
\hline \multirow[b]{2}{*}{ Strain } & \multirow{2}{*}{$\begin{array}{l}\text { Carbon } \\
\text { source }\end{array}$} & \multirow{2}{*}{$\begin{array}{l}\text { Dry cell } \\
\text { weight } \\
\left(g /^{-1}\right)\end{array}$} & \multirow{2}{*}{$\begin{array}{c}\text { PHA } \\
\text { content } \\
\text { (wt\%) }\end{array}$} & \multicolumn{2}{|c|}{$\begin{array}{l}\text { PHA compo- } \\
\text { sition } \\
(m o l \%)^{a}\end{array}$} & \multirow{2}{*}{$\begin{array}{c}\text { Number-average mole- } \\
\text { cular weight }\left(\mathrm{g} \mathrm{mol}^{-1}\right) \\
(P D I)^{b}\end{array}$} \\
\hline & & & & $3 H B$ & $3 H V$ & \\
\hline \multicolumn{7}{|c|}{ Colwellia sp. (JAMM-0421) } \\
\hline & Glucose & $1.7 \pm 0.1$ & $2.0 \pm 0.1$ & 71.0 & 29.0 & $340 \times 10^{3}(1.5)$ \\
\hline & Fructose & $1.7 \pm 0.1$ & $2.7 \pm 0.1$ & 89.5 & 10.5 & $300 \times 10^{3}(2.8)$ \\
\hline & Guconate & $0.6 \pm 0.1$ & trace & 100 & - & $99 \times 10^{3}(1.9)$ \\
\hline & $\begin{array}{l}\text { Jatropha } \\
\text { oil }\end{array}$ & $1.4 \pm 0.2$ & $16.4 \pm 1.1$ & 96.0 & 4.0 & $170 \times 10^{3}(2.9)$ \\
\hline & $\begin{array}{l}\text { soybean } \\
\text { oil }\end{array}$ & $1.3 \pm 0.1$ & $10.9 \pm 1.6$ & 97.6 & 2.4 & $230 \times 10^{3}(3.0)$ \\
\hline \multicolumn{7}{|c|}{ Moritella sp. (JCM21335) } \\
\hline & Glucose & $0.7 \pm 0.2$ & - & - & - & - \\
\hline & Fructose & $1.3 \pm 0.1$ & $3.4 \pm 1.0$ & 90.5 & 9.5 & $120 \times 10^{3}(1.8)$ \\
\hline & Gluconate & $0.6 \pm 0.1$ & $0.7 \pm 0.1$ & - & - & - \\
\hline & $\begin{array}{l}\text { Jatropha } \\
\text { oil }\end{array}$ & $2.4 \pm 0.3$ & $0.7 \pm 0.1$ & ND & ND & $1000-30000$ \\
\hline & $\begin{array}{l}\text { Soybean } \\
\text { oil }\end{array}$ & $1.2 \pm 0.1$ & $1.6 \pm 0.5$ & ND & ND & $1000-30000$ \\
\hline \multicolumn{7}{|c|}{ Shewanella surugensis (JAMM-0036) } \\
\hline & Gucose & $0.7 \pm 0.1$ & - & - & - & - \\
\hline & Fructose & $0.1 \pm 0.1$ & Trace & - & - & - \\
\hline & Gluconate & $0.1 \pm 0.1$ & - & - & - & - \\
\hline & $\begin{array}{l}\text { Jatropha } \\
\text { oil }\end{array}$ & $1.9 \pm 0.3$ & $0.4 \pm 0.2$ & Trace & - & $1.0 \times 10^{3}(1.1)$ \\
\hline & $\begin{array}{l}\text { Soybean } \\
\text { oil }\end{array}$ & $1.2 \pm 0.2$ & $0.6 \pm 0.2$ & Trace & - & $1.0 \times 10^{3}(1.1)$ \\
\hline
\end{tabular}

Abbreviations: 3HB, $(R)$-3-hydroxybutyrate (3HB) 3HV, $(R)$-3-hydroxyvalerate; ND, not determined; PDI, polydispersity index; PHA, poly(hydroxyalkanoate).

${ }^{a}$ Determined by ${ }^{1} \mathrm{H}$ nuclear magnetic resonance spectroscopy.

bPolydispersity index (determined by gel-permeation chromatography).

S. surugensis accumulated oligomeric PHAs when a plant oil was used as the sole source of carbon (Table 1). The ${ }^{1} \mathrm{H}$ NMR spectra showed that the structure of the oligomers synthesized by $S$. surugensis was similar to that of the polymer synthesized by Moritella sp. (Figures $4 \mathrm{~b}$ and $\mathrm{c}$ ). However, in the ${ }^{1} \mathrm{H}$ NMR spectra of the polymer synthesized by $S$. surugensis, the peaks at around $\delta=2.55$ p.p.m., which were assigned to methylene protons of the main chain, differed from those in the corresponding spectrum of the PHA from the Moritella sp. The molecular weight of the polymer synthesized by S. surugensis was markedly lower and its polydispersity index was markedly narrower than the corresponding values for the polymer from the Moritella sp. (Figure 3c). Because of the low molecular weight of the oligomeric product, we expected to be able to characterize the chain-end structures of the polymer by ${ }^{1} \mathrm{H}$ NMR spectroscopy; however, no peaks originating from the chain ends could be assigned. ${ }^{21,22}$ This might be because the synthesized polymers were blends of oligomers with various chemical structures, rather than pure copolymers. An influence of the PhaC on the molecular weight of the synthesized PHA has previously been reported for a series of mutant PhaCs from A. caviae and Pseudomonas sp. 61-3. ${ }^{23,24}$ These studies found that a difference of one order of magnitude in the molecular weight of PHAs could be induced by mutation of the PhaC. Alteration of the function of the PhaC cannot, therefore, completely explain the observed reduction in the molecular weight of the PHA to that of the oligomer synthesized 


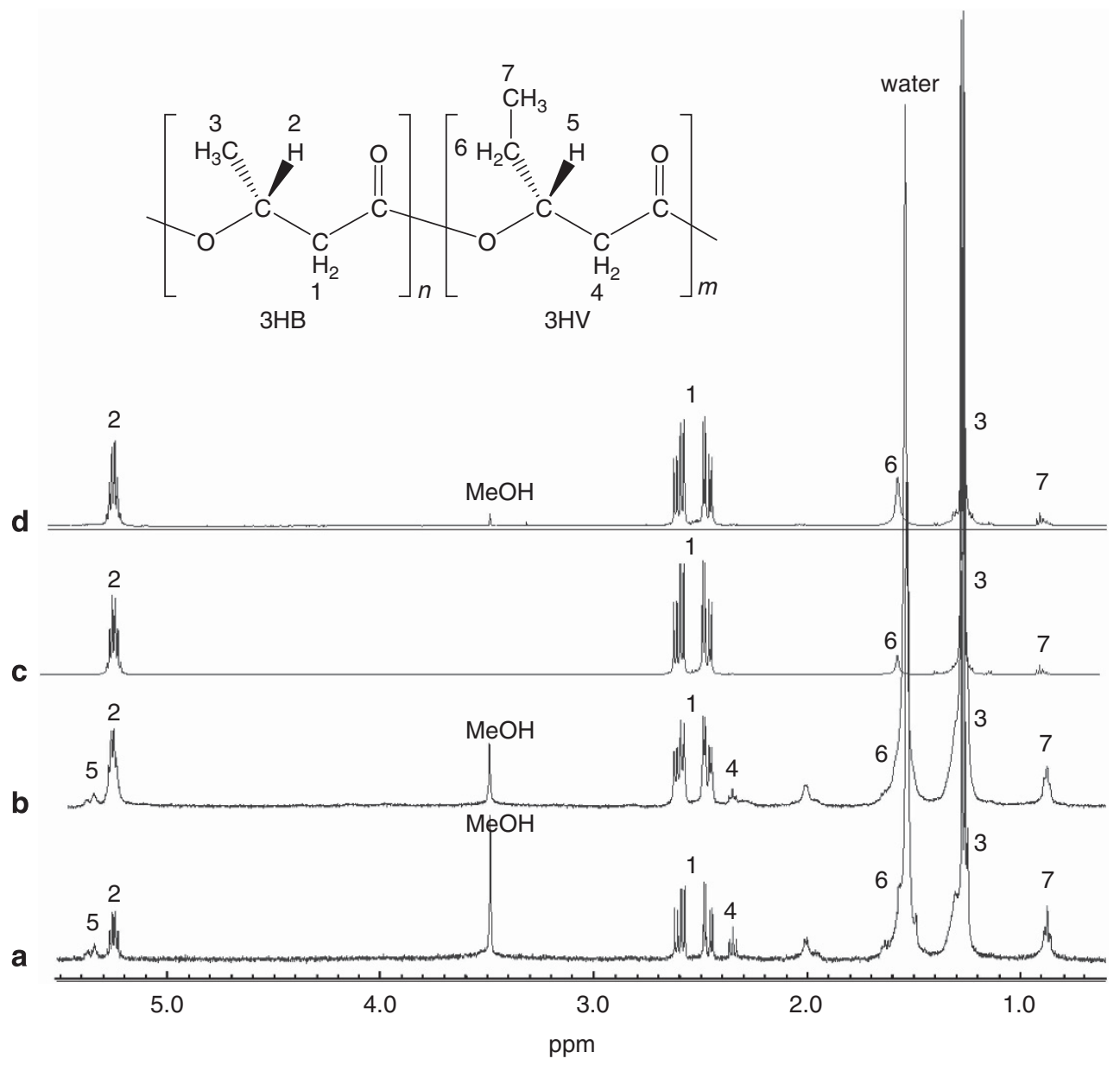

Figure $2{ }^{1} \mathrm{H}$ NMR spectra of samples of PHA synthesized by Colwellia sp. from (a) glucose, (b) fructose, (c) soybean oil, or (d) jatropha oil.

by S. surugensis with plant oils as the sole source of carbon $\left(\sim 1000 \mathrm{~g} \mathrm{~mol}^{-1}\right)$. The metabolic pathway of the strain, especially its $\beta$-oxidation pathway, must also affect the molecular weight of PHA. No previous method has been established for the biosynthesis of oligomeric PHAs, which might be useful as raw materials for cosmetics or as pharmaceutical products. ${ }^{25}$ The synthesis of the oligomeric polyester from plant oils by $S$. surugensis therefore has potential as a new method for producing oligomeric PHAs for practical use.

The major difference among the three genera is found in their biosynthesis behavior for PUFAs, such as EPA or DHA. ${ }^{26}$ As explained in the introduction, organisms of the genus Moritella generally biosynthesize DHA, whereas those of the genera Colwellia and Shewanella produce EPA.,27 Both bacterial PUFAs are synthesized by polyketide synthase system, and DHA is synthesized via EPA. ${ }^{4,26}$ Although we could not evaluate how differences in the biosynthesis of PUFAs contributed to PHA synthesis in the current study, deep-sea bacteria with different pathways for PUFA synthesis did show differences in their productivities of PHAs. Under some culture conditions, cell growth of the strains was insufficient to permit evaluation of their PHA productivities (see Supplementary Tables S2-S4). Furthermore, the synthesized polymers could not be adequately characterized to permit determination of their chemical and chain-end structures. To determine these details of PHA productivity of the deep-sea strains in future experiments, we plan to perform large-scale cultivations (for example, 10-liter-scale fermentations)

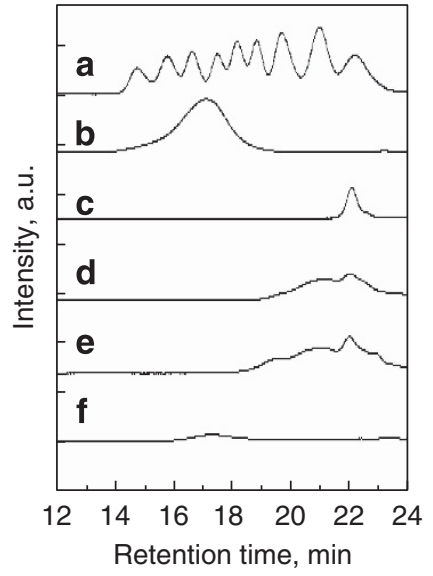

Figure 3 Gel-permeation chromatographic retention times of (a) polystyrene standards (molecular weights: 3 148,843, $1074876,460595,156528$, $66001,28517,10112,3252$, and $1319 \mathrm{~g} \mathrm{~mol}^{-1}$ ) and of PHA samples synthesized from various substrates by deep-sea strains: (b) from soybean oil by Colwellia sp., (c) from soybean oil by Shewanella surugensis, (d) from soybean oil by Moritella sp., (e) from jatropha oil, and (f) from fructose by Moritella sp.

under aerobic and anaerobic conditions and also to construct transgenic R. eutropha harboring samples of PhaCs originating from deep-sea bacteria to evaluate their substrate specificities. 


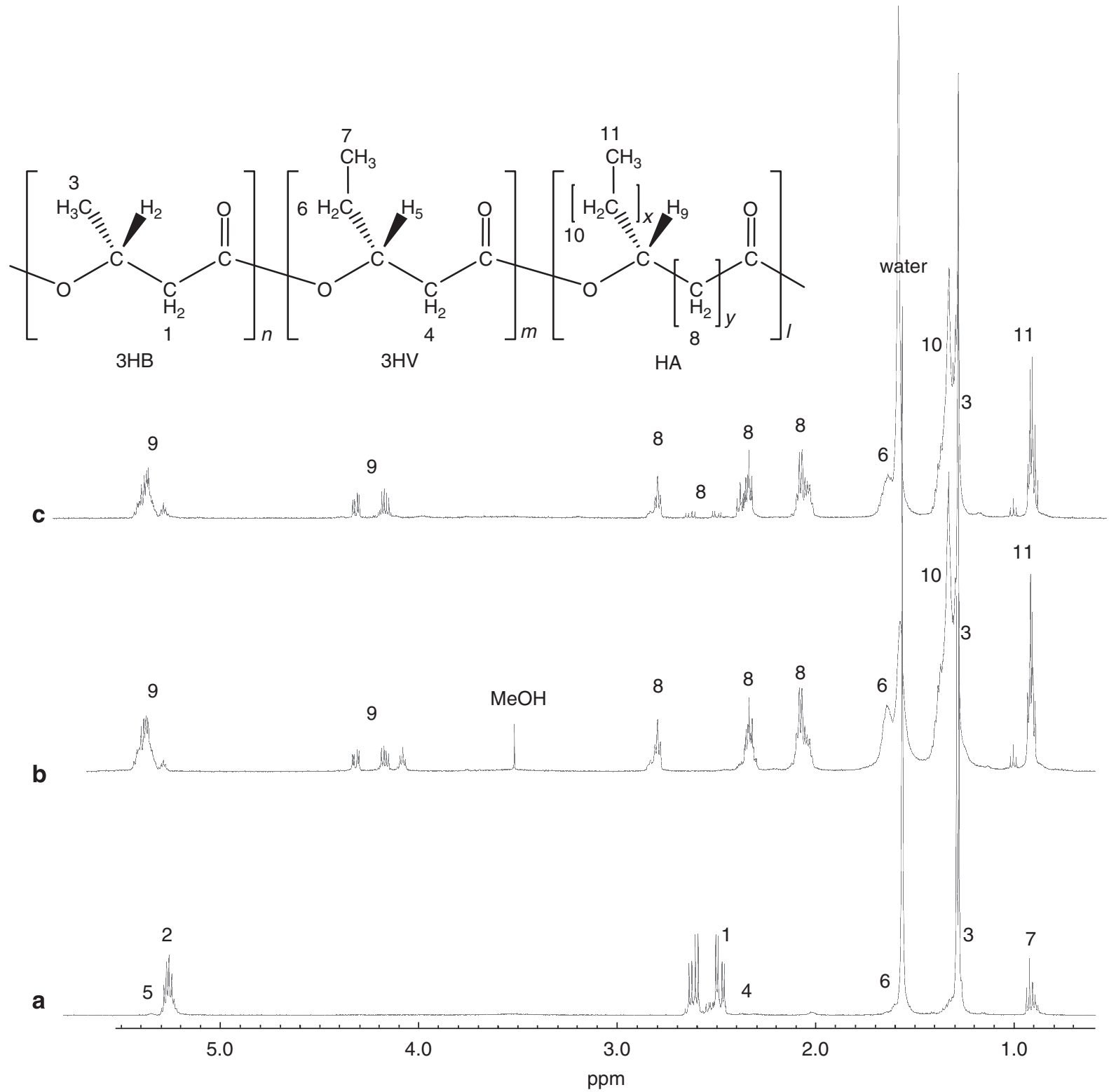

Figure $4{ }^{1} \mathrm{H}$ nuclear magnetic resonance spectra of oligomers and polymers synthesized (a) by Moritella sp. from fructose, (b) by Moritella sp. from soybean oil, and (c) by Shewanella surugensis from glucose. A full color version of this figure is available at Polymer Journal online.

\section{PhaCs from deep-sea strains}

PhaCs are key enzymes for the synthesis of PHAs and they have been classified into four classes with respect to their amino-acid sequences. ${ }^{15}$ Class I PhaCs consist of single subunits with molecular weights between 61 and $68 \mathrm{kDa}$. The PhaCs from $R$. eutropha and A. caviae, which have been widely studied, are known to be Class I PhaCs that exhibit different substrate specificities. ${ }^{15,20,28,29}$ The PhaC from A. caviae is an exceptional PhaC in Class I because of its low similarity (approximately $45 \%$ ) to the other members of the group of Class I PhaCs and because of its substrate specificity for $\mathrm{C}_{4}$ and $\mathrm{C}_{6}$ monomers. ${ }^{30,31}$ The genomes of the deep-sea bacteria Shewanella halifaxensis, S. pealeana, and Colwellia psychrerythraea have been sequenced, and the appropriate $\mathrm{PhaC}$ sequences have been identified. On the basis of their amino-acid sequences, the PhaCs from S. halifaxensis, S. pealeana, and C. psychrerythraea have been classified as Class I PhaCs. To evaluate the difference between the amino-acid sequences of PhaCs of deep-sea bacteria and those of soil bacteria, multiple alignments of the amino-acid sequences of PhaCs from S. halifaxensis, S. pealeana, and C. psychrerythraea with those from A. caviae and R. eutropha H16 were performed (Figure 5). The PhaC genes of S. halifaxensis and S. pealeana showed 92\% identities in terms of their amino-acid sequences, which confirmed the PhaCs within a particular genus show high degrees of identity in terms of their amino-acid sequences. The amino-acid sequence of the PhaC from $R$. eutropha H16 showed 38, 42, and 43\% identities to those of the PhaCs from C. psychrerythraea, S. halifaxensis, and S. pealeana, respectively. The amino-acid sequence of $\mathrm{PhaC}$ from A. caviae showed 40,55 , and $54 \%$ identities to those from C. psychrerythraea, S. halifaxensis, and S. pealeana, respectively. The identities between the $\mathrm{PhaC}$ from $C$. psychrerythraea and those from the two types of Shewanella were approximately $42 \%$. Based on the yields, compositions, and molecular weights of PHA 


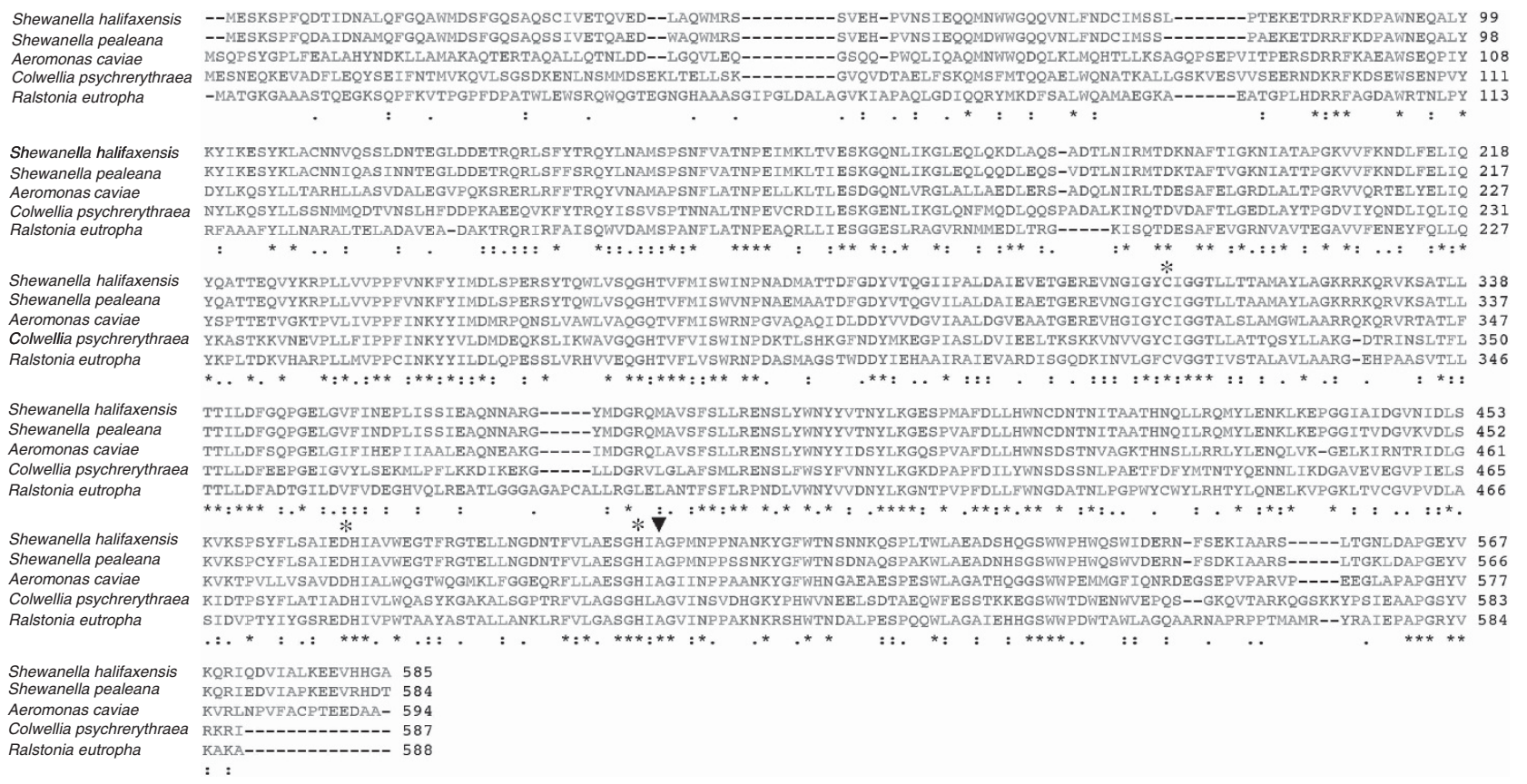

Figure 5 Multiple alignment of poly(hydroxyalkanoate) (PHA) synthases (PhaCs) originating from Shewanella halifaxensis, Shewanella pealeana, Aeromonas caviae, Colwellia psychrerythraea, and Ralstonia eutropha H16. Asterisks denote a putative catalytic triad. The arrow indicates Ala-505 for PhaC from A. caviae. A full color version of this figure is available at Polymer Journal online.

(Supplementary Tables S1 and S2-S4), differences in the degree of identity between soil bacteria and deep-sea bacteria might not be sufficient to explain the differences in the functions of their respective PhaCs.

Several groups have reported effects of mutations of PhaCs, such as PhaCs from A. caviae, Pseudomonas sp. 61-3, R. eutropha, or Allochromatium vinosum. . $^{23,243-37}$ A mutation at position Ala505 (indicated by an arrow in Figure 5) of the PhaC from A. caviae affected the composition and molecular weight of the PHA. ${ }^{23}$ Position Ala505 is a neighboring position to an active site (His503), as indicated by the asterisk in Figure 5. The deep-sea strains shown in Figure 5 have an alanine moiety in the position corresponding to Ala505 of PhaC from A. caviae, implying that this position is not of major significance in terms of controlling the molecular weight of PHA over several orders of magnitude. This finding and the results in Table 1, taken together, indicate that PhaCs originating from deep-sea bacteria have the potential to regulate the molecular weight of PHAs and to take up new monomer units, especially when the $\beta$-oxidation pathway is used to produce monomers similar to those deep-sea bacteria. The present study also showed that PhaCs from deep-sea bacteria are useful research targets in producing novel types of PHA.

\section{CONCLUSIONS}

This is the first investigation of the production of PHAs at normal pressures by three genera of deep-sea bacteria: Colwellia, Moritella, and Shewanella. We attempted to produce PHAs by using 33 strains of deep-sea bacteria with glucose, fructose, gluconate, or with plant oils as the sole source of carbon. In several combinations of strain and carbon source, the deep-sea bacteria successfully accumulated PHAs that contained different monomer units and had different molecular weights from those of the corresponding polymers produced by soil bacteria. It is noteworthy that with plant oils as sole sources of carbon, S. surugensis accumulated oligomeric PHAs. Hydroxyalkanoate units were also incorporated into the PHA accumulated by a
Moritella sp. JCM21335 strain when a plant oil was used as the carbon source. This finding provides a potential method for controlling the biosynthesis of oligomeric PHAs, useful as raw materials for cosmetics or as pharmaceutical products, by using deep-sea bacteria and/or PhaCs from deep-sea bacteria. Furthermore, this new insight provides a biotechnological option for the production of various polymeric materials and chemicals, including PHA and its oligomers, by deepsea bacteria, permitting the possible efficient utilization of deep-sea bioresources.

\section{ACKNOWLEDGEMENTS}

This work was supported by a grant for the RIKEN Biomass Engineering Program.

1 Okuyama, H., Orikasa, Y., Nishida, T., Watanabe, K. \& Morita, N. Bacterial genes responsible for the biosynthesis of eicosapentaenoic and docosahexaenoic acids and their heterologous expression. Appl. Environ. Microbiol. 73, 665-670 (2007).

2 Wada, M., Fukunaga, N. \& Sasaki, S. Aerobic synthesis of unsaturated fatty-acids in a psychrotrophic bacterium, Pseudomonas sp. strain E-3, having two mechanisms for unsaturated fatty acid synthesis. J. Gen. Appl. Microbiol. 37, 355-362 (1991).

3 Lee, T. H., Hoover, R. L., Williams, J. D., Sperling, R. I., Ravalese, J. III, Spur, B. W., Robinson, D. R., Corey, E. J., Lewis, R. A. \& Austen, K. F. Effect of dietary enrichment with eicosapentaenoic and docosahexaenoic acids on in vitro neutrophil and monocyte leukotriene generation and neutrophil function. N. Engl. J. Med. 312, 1217-1224 (1985).

4 Pereira, S. L., Leonard, A. E. \& Mukerji, P. Recent advances in the study of fatty acid desaturases from animals and lower eukaryotes. Prostaglandins Leukot. Essent. Fatty Acids 68, 97-106 (2003).

5 Krembs, C., Eicken, H., Junge, K. \& Deming, J. W. High concentrations of exopolymeric substances in Arctic winter sea ice: implications for the polar ocean carbon cycle and cryoprotection of diatoms. Deep-Sea Res. Part / 49, 2163-2181 (2002).

6 Methe, B. A., Nelson, K. E., Deming, J. W., Momen, B., Melamud, E., Zhang, X., Moult, J., Madupu, R., Nelson, W. C., Dodson, R. J., Brinkac, L. M., Daugherty, S. C., Durkin, A. S., DeBoy, R. T., Kolonay, J. F., Sullivan, S. A., Zhou, L., Davidsen, T. M., Wu, M., Huston, A. L., Lewis, M., Weaver, B., Weidman, J. F., Khouri, H., Utterback, T. R., Feldblyum, T. V. \& Fraser, C. M. The psychrophilic lifestyle as revealed by the genome sequence of Colwellia psychrerythraea $34 \mathrm{H}$ through genomic and proteomic analyses. Proc. Natl. Acad. Sci. USA 102, 10913-10918 (2005). 
7 Sukovich, D. J., Seffernick, J. L., Richman, J. E., Hunt, K. A., Gralnick, J. A. \& Wackett, L. P. Structure, function, and insights into the biosynthesis of a head-to-head hydrocarbon in Shewanella oneidensis strain MR-1. Appl. Environ. Microbiol. 76, 3842-3849 (2010).

8 Doi, Y. Microbial Polyesters (VCH, New York, USA, 1990).

9 Marchessault, R.H. \& Yu, G. in Biopolymers, Volume 3b, Polyesters II: Properties and Chemical Synthesis (eds Doi, Y. \& Steinbüchel, A.) (Wiley-VCH, Weinhelm, Germany, 2001).

10 Lenz, R. W. \& Marchessault, R. H. Bacterial polyesters: biosynthesis, biodegradable plastics and biotechnology. Biomacromolecules 6, 1-8 (2005).

11 Iwata, T., Aoyagi, Y., Fujita, M., Yamane, H., Doi, Y., Suzuki, Y., Takeuchi, A. \& Uesugi, $\mathrm{K}$. Processing of a strong biodegradable poly[( $R)$-3-hydroxybutyrate] fiber and a new fiber structure revealed by micro-beam X-ray diffraction with synchrotron radiation. Macromol. Rapid Commun. 25, 1100-1104 (2004).

12 Pohlmann, A., Fricke, W. F., Reinecke, F., Kusian, B., Liesegang, H., Cramm, R., Eitinger, T., Ewering, C., Pötter, M., Schwartz, E., Strittmatter, A., Voß, I., Gottschalk, G., Steinbüchel, A., Friedrich, B. \& Bowien, B. Genome sequence of the bioplasticproducing 'Knallgas' bacterium Ralstonia eutropha H16. Nat. Biotechnol. 24 1257-1262 (2006).

13 Fiedler, S., Steinbuchel, A. \& Rehm, B. H. The role of the fatty acid beta-oxidation multienzyme complex from Pseudomonas oleovorans in polyhydroxyalkanoate biosynthesis: molecular characterization of the Fadba operon from P. oleovorans and of the enoyl-CoA hydratase genes PhaJ from P. oleovorans and Pseudomonas putida. Arch. Microbiol. 178, 149-160 (2002).

14 Tsuge, T., Fukui, T., Matsusaki, H., Taguchi, S., Kobayashi, G., Ishizaki, A. \& Doi, Y. Molecular cloning of two $(R)$-specific enoyl-CoA hydratase genes from Pseudomonas aeruginosa and their use for polyhydroxyalkanoate synthesis. FEMS Microbiol. Lett. 184, 193-198 (2000).

15 Rehm, B. H. Polyester synthases: natural catalysts for plastics. Biochem. J. 376, 15-33 (2003).

16 Numata, K. \& Doi, Y. Biosynthesis of polyhydroxyalkanaotes by a novel facultatively anaerobic Vibrio sp. under marine conditions. Mar. Biotechnol. 14, 323-331 (2012).

17 Altschul, S. F., Gish, W., Miller, W., Myers, E. W. \& Lipman, D. J. Basic local alignment search tool. J. Mol. Biol. 215, 403-410 (1990).

18 Chuah, J.-A., Yamada, M., Taguchi, S., Sudesh, K., Doi, Y. \& Numata, K. Biosynthesis and characterization of polyhydroxyalkanoate containing 5-hydroxyvalerate units: effects of $5 \mathrm{HV}$ units on biodegradability, cytotoxicity, mechanical and thermal properties. Polym. Degrad. Stab. 98, 331-338 (2013).

19 Doi, Y., Tamaki, A., Kunioka, M. \& Soga, K. Biosynthesis of terpolyesters of 3-hydroxybutyrate, 3-hydroxyvalerate, and 5-hydroxyvalerate in Alcaligenes eutrophus from 5-chloropentanoic and pentanoic acids. Makromol. Chem. Rapid Commun 8, 631-635 (1987)

20 Fukui, T. \& Doi, Y. Cloning and analysis of the poly(3-hydroxybutyrate-co-3hydroxyhexanoate) biosynthesis genes of Aeromonas caviae. J. Bacteriol. 179, 4821-4830 (1997).

21 Yamanaka, K., Kimura, Y., Aoki, T. \& Kudo, T. End-group analysis of bacterially produced poly(3-hydroxybutyrate): discovery of succinate as the polymerization starter. Macromolecules 42, 4038-4046 (2009).

$22 \mathrm{Li}$, J., Uzawa, J. \& Doi, Y. Conformational behavior of methyl (3R)-3-22 butanoate in solutions: effect of intramolecular hydrogen bond. Bull. Chem. Soc. Jpn. 70, 1887-1893 (1997)
23 Tsuge, T., Watanabe, S., Sato, S., Hiraishi, T., Abe, H., Doi, Y. \& Taguchi, S. Variation in copolymer composition and molecular weight of polyhydroxyalkanoate generated by saturation mutagenesis of Aeromonas caviae PHA synthase. Macromol. Biosci. 7 , 846-854 (2007).

24 Tsuge, T., Yano, K., Imazu, S., Numata, K., Kikkawa, Y., Abe, H., Taguchi, S. \& Doi, Y. Biosynthesis of polyhydroxyalkanoate (PHA) copolymer from fructose using wild-type and laboratory-evolved PHA synthases. Macromol. Biosci. 5, 112-117 (2005).

25 Pawan, G. L. \& Semple, S. J. Effect of 3-hydroxybutyrate in obese subjects on very-lowenergy diets and during therapeutic starvation. Lancet 321, 15-17 (1983).

26 Metz, J. G., Roessler, P., Facciotti, D., Levering, C., Dittrich, F., Lassner, M., Valentine, R., Lardizabal, K., Domergue, F., Yamada, A., Yazawa, K., Knauf, V. \& Browse, J. Production of polyunsaturated fatty acids by polyketide synthases in both prokaryotes and eukaryotes. Science 293, 290-293 (2001).

27 Yano, Y., Nakayama, A. \& Yoshida, K. Distribution of polyunsaturated fatty acids in bacteria present in intestines of deep-sea fish and shallow-sea poikilothermic animals. Appl. Environ. Microbiol. 63, 2572-2577 (1997).

28 Fukui, T., Yokomizo, S., Kobayashi, G. \& Doi, Y. Co-expression of polyhydroxyalkanoate synthase and $(R)$-enoyl-CoA hydratase genes of Aeromonas caviae establishes copolyester biosynthesis pathway in Escherichia coli. FEMS Microbiol. Lett. 170, 69-75 (1999).

29 Numata, K., Motoda, Y., Watanabe, S., Tochio, N., Kigawa, T. \& Doi, Y. Active intermediates of polyhydroxyalkanoate synthase from Aeromonas caviae in polymerization reaction. Biomacromolecules 13, 3450-3455 (2012).

30 Steinbüchel, A., Hustede, E., Liebergesell, M., Pieper, U., Timm, A. \& Valentin, H. Molecular basis for biosynthesis and accumulation of polyhydroxyalkanoic acids in bacteria. FEMS Microbiol. Rev. 9, 217-230 (1992) corrigendum ibid. 10, 347-350 (1993).

31 Liebergesell, M. \& Steinbüchel, A. Cloning and molecular analysis of the poly(3hydroxybutyric acid) biosynthetic genes of Thiocystis violacea. Appl. Microbiol. Biotechnol. 38, 493-501 (1993).

32 Jia, Y., Yuan, W., Wodzinska, J., Park, C., Sinskey, A. J. \& Stubbe, J. Mechanistic studies on Class I polyhydroxybutyrate (PHB) synthase from Ralstonia eutropha: Class I and III synthases share a similar catalytic mechanism. Biochemistry 40, 1011-1019 (2001).

33 Kichise, T., Taguchi, S. \& Doi, Y. Enhanced accumulation and changed monomer composition in polyhydroxyalkanoate (PHA) copolyester by in vitro evolution of Aeromonas caviae PHA synthase. Appl. Environ. Microbiol. 68, $2411-2419$ (2002).

$34 \mathrm{Li}$, P., Chakraborty, S. \& Stubbe, J. Detection of covalent and noncovalent intermediates in the polymerization reaction catalyzed by a C149S Class III polyhydroxybutyrate synthase. Biochemistry 48, 9202-9211 (2009).

35 Normi, Y. M., Hiraishi, T., Taguchi, S., Abe, H., Sudesh, K., Najimudin, N. \& Doi, Y. Characterization and properties of G4X mutants of Ralstonia eutropha PHA synthase for poly(3-hydroxybutyrate) biosynthesis in Escherichia coli. Macromol. Biosci. 5, 197-206 (2005).

36 Tian, J., Sinskey, A. J. \& Stubbe, J. Detection of intermediates from the polymerization reaction catalyzed by a D302A mutant of Class III polyhydroxyalkanoate (PHA) synthase. Biochemistry 44, 1495-1503 (2005).

37 Tsuge, T., Watanabe, S., Shimada, D., Abe, H., Doi, Y. \& Taguchi, S. Combination of N149S and D171G mutations in Aeromonas caviae polyhydroxyalanoate synthase and impact on polyhydroxyalkanoate biosynthesis. FEMS Microbiol. Lett. 277, 217-222 (2007).

Supplementary Information accompanies the paper on Polymer Journal website (http://www.nature.com/pj) 